OPEN ACCESS

Edited by:

Andrea Baldi,

Dutch Institute for Fundamental Energy Research, Netherlands

Reviewed by:

Peter Ngene,

Utrecht University, Netherlands Elsa Callini,

Comet ebeam Technologies, Switzerland

*Correspondence: Claudia Zlotea

claudia.zlotea@icmpe.cnrs.fr

Specialty section:

This article was submitted to Hydrogen Storage and Production,

a section of the journal

Frontiers in Energy Research

Received: 20 April 2016

Accepted: 29 May 2016

Published: 27 June 2016

Citation:

Zlotea C, Oumellal Y, Provost $K$ and Ghimbeu CM (2016) Experimental

Challenges in Studying

Hydrogen Absorption in Ultrasmall Metal Nanoparticles.

Front. Energy Res. 4:24. doi: 10.3389/fenrg.2016.00024

\section{Experimental Challenges in Studying Hydrogen Absorption in Ultrasmall Metal Nanoparticles}

\author{
Claudia Zlotea ${ }^{1 *}$, Yassine Oumellall ${ }^{1}$, Karine Provost $^{1}$ and Camelia Matei Ghimbeu ${ }^{2}$ \\ ${ }^{1}$ CNRS, Institut de Chimie et des Matériaux Paris-Est (UMR7182), Université Paris Est, Thiais, France, ${ }^{2}$ CNRS, Institut de \\ Science des Matériaux de Mulhouse (UMR7361), Université de Strasbourg, Université de Haute-Alsace, Mulhouse, France
}

Recent advances on synthesis, characterization, and hydrogen absorption properties of ultrasmall metal nanoparticles (defined here as objects with average size $\leq 3 \mathrm{~nm}$ ) are briefly reviewed in the first part of this work. The experimental challenges encountered in performing accurate measurements of hydrogen absorption in $\mathrm{Mg}$ - and noble metal-based ultrasmall nanoparticles are addressed. The second part of this work reports original results obtained for ultrasmall bulk-immiscible $\mathrm{Pd}-\mathrm{Rh}$ nanoparticles. Carbonsupported $\mathrm{Pd}-\mathrm{Rh}$ nanoalloys in the whole binary chemical composition range have been successfully prepared by liquid impregnation method followed by reduction at $300^{\circ} \mathrm{C}$. EXAFS investigations suggested that the local structure of these nanoalloys is partially segregated into Rh-rich core and Pd-rich surface coexisting within the same nanoparticles. Downsizing to ultrasmall dimensions completely suppresses the hydride formation in Pd-rich nanoalloys at ambient conditions, contrary to bulk and larger nanosized (5-6 nm) counterparts. The ultrasmall $\mathrm{Pd}_{90} \mathrm{Rh}_{10}$ nanoalloy can absorb hydrogen-forming solid solutions under these conditions, as suggested by in situ X-ray diffraction (XRD). Apart from this composition, common laboratory techniques, such as in situ $X R D$, DSC, and $\mathrm{PCl}$, failed to clarify the hydrogen interaction mechanism: either adsorption on developed surfaces or both adsorption and absorption with formation of solid solutions. Concluding insights were brought by in situ EXAFS experiments at synchrotron: ultrasmall $\mathrm{Pd}_{75} \mathrm{Rh}_{25}$ and $\mathrm{Pd}_{50} \mathrm{Rh}_{50}$ nanoalloys absorb hydrogen-forming solid solutions at ambient conditions. Moreover, the hydrogen solubility in these solid solutions is higher with increasing Pd content, and this trend can be understood in terms of hydrogen preferential occupation in the Pd-rich regions, as suggested by in situ EXAFS. The Rh-rich nanoalloys ( $\mathrm{Pd}_{25} \mathrm{Rh}_{75}$ and $\mathrm{Pd}_{10} \mathrm{Rh}_{90}$ ) only adsorb hydrogen on the developed surface of ultrasmall nanoparticles. In summary, in situ characterization techniques carried out at large-scale facilities are unique and powerful tools for in-depth investigation of hydrogen interaction with ultrasmall nanoparticles at local level.

Keywords: ultrasmall metal nanoparticles, hydride, solid solutions, hydrogen, X-ray absorption spectroscopy

\section{INTRODUCTION}

The control of materials at the nanoscale comprises a new frontier of opportunity in science and technology. The research interest in metallic nanoparticles lies in their many fascinating applications discovered in the recent years (Roduner, 2006). Promises and possibilities are wide ranging: nanocatalysts open new routes to various products, nanomagnets will store information for 
modern computers, and nanoparticles will help drug delivery and medical imaging. However, the use of free nanoparticles raises the issue of their stability toward coalescence. From extensive research on the synthesis of nanoparticles, it became obvious that stabilized nanoparticles into light and porous supports/scaffolds are appropriate candidates to avoid/limit coalescence during utilization in the foreseen applications (de Jongh and Adelhelm, 2010; de Jongh et al., 2013; Zlotea and Latroche, 2013).

On another perspective, future energy landscape stringently requires the use of less-pollutant energy resources and the reduction of greenhouse emissions from fossil fuels. The emerging clean energy field comprises different renewable resources and hydrogen as one of the possible energy carriers (Eberle et al., 2009; Borgschulte, 2016). Three main challenges have been recently identified related to this field: analytical, materials, and system-related challenges (Borgschulte, 2016). The implementation of time- and space-resolved analytical methods with femtosecond and nanometer resolutions, respectively, is opening new perspectives for in-depth characterization of functional materials. Similar to recent trends in materials science, this particular field is more and more reliant on novel nanomaterials due to their unique properties. Light and nanostructured materials (nanosized metals/alloys and hydrides along with nanoporous solids) are currently explored for their promising solid-state hydrogen storage and electrochemical conversion properties (Bérubé et al., 2007; de Jongh and Adelhelm, 2010; Cheng et al., 2012; Oumellal et al., 2014; Crivello et al., 2016; Sartori et al., 2016).

In this context, the insertion of hydrogen in metal nanoparticles is an important topic of fundamental research for both storage and sensing devices. However, the experimental study of hydrogen absorption in nanoparticles is very challenging, especially when dealing with ultrasmall nanoparticles. The latter ones are defined here as nanoparticles with average particle size $\leq 3 \mathrm{~nm}$. The potential use of these metallic nanoparticles is largely unexplored in the hydrogen storage field, whereas the mainstream of studies on these materials is driven by heterogeneous catalysis. Both physicochemical properties of ultrasmall nanoparticles (structure, nanostructure, morphology, dispersion, etc.) and hydrogen absorption/desorption are difficult to characterize using classical laboratory techniques.

This report discusses the technical challenges in the synthesis and characterization of physicochemical properties of supported ultrasmall nanoparticles and their interaction with hydrogen gas (adsorption on surface, absorption in the volume with formation of solid solutions, and hydride phase). This is a fundamental study that focuses on the comprehension of hydrogen sorption mechanisms in ultrasmall nanoparticles. The first part will briefly review recent advances in the research on ultrasmall nanoparticles for hydrogen storage (both light- and noble metal-based nanoparticles). The second part will develop original results obtained on carbon-supported ultrasmall $\mathrm{Pd}-\mathrm{Rh}$ nanoalloys $(\leq 3 \mathrm{~nm})$. Besides classical laboratory methods, fine characterization techniques based on large-scale facilities are requested for the in situ exploration of hydrogen insertion in these ultrasmall nanoparticles.

\section{STATE OF THE ART: SYNTHESIS AND HYDROGEN ABSORPTION IN ULTRASMALL NANOPARTICLES}

This first part will briefly review recent results reported for two types of ultrasmall nanoparticles: $\mathrm{MgH}_{2}$ and noble metal-based supported clusters.

\section{Synthesis}

The synthesis of ultrasmall nanoparticles $(\leq 3 \mathrm{~nm})$ supported/ embedded into porous hosts is very complex mainly due to coalescence issue and uncontrolled growth of nanoparticles. Among various methods for the synthesis of supported metal nanoparticles, the most widespread approach is the incipient wetness impregnation method: the porous support (typically carbon and metal organic framework) is impregnated with a solution of metal precursor, which is subsequently reduced using different reducing agents $\left(\mathrm{H}_{2}, \mathrm{NaBH}_{4}\right.$, etc.) (Wilcoxon and Abrams, 2006; Roesler and Fischer, 2015). Another interesting technique is the melt infiltration of low temperature melting metals, such as Mg, into different porous carbon hosts (de Jongh and Eggenhuisen, 2013; Au et al., 2014). For both synthetic method many experimental parameters are plying a crucial role to ensure the stability toward coalescence and the high dispersion of such nanoparticles on the support: the porosity/surface chemistry of the support, the nature of metal precursor, the metal loading, and the synthesis conditions: temperature, reducing agent, etc. (de Jongh et al., 2007; Konarova et al., 2012; Zhao et al., 2012; Zlotea and Latroche, 2013).

For the preparation of supported $\mathrm{MgH}_{2}$ nanoparticles by incipient wetness impregnation method, the porous host is impregnated with a commercial solution of $\mathrm{MgBu}_{2}$ followed by hydrogenation under 50 bar $\mathrm{H}_{2}$ pressure at $150^{\circ} \mathrm{C}$ (Nielsen et al., 2009; Zhang et al., 2009; Zlotea et al., 2011). Recently, we have clearly demonstrated that only the use of microporous carbon with high specific surface area $\left(\sim 2300 \mathrm{~m}^{2} / \mathrm{g}\right)$ is favorable for the preparation of ultrasmall $\mathrm{MgH}_{2}$ nanoparticles $(\leq 3 \mathrm{~nm}$ ) (Zlotea et al., 2015a). Moreover, the average nanoparticle size is strongly related to the metal amount and can be tuned from 1.3 to $3.0 \mathrm{~nm}$ for 15 and $25 \mathrm{wt} \%$ of $\mathrm{Mg}$, respectively. The use of mesoporous carbon supports and/or high Mg loadings (>25 wt\%) strongly increases the average size and broaden the particle size distribution (2-50 nm) (Oumellal et al., 2014). An important experimental difficulty is related to the air sensitivity of $\mathrm{MgH}_{2}$ nanoparticle. All characterization measurements have to be performed under an inert atmosphere using air-tight sample holders.

The synthesis of ultrasmall noble metal-based nanoparticles supported on a porous host is well documented due to extensive study of such materials for catalysis and hydrogen sorption (Campesi et al., 2008; Narehood et al., 2009; Zlotea et al., 2010a; Contescu et al., 2011). Typically, a metal salt is used as precursor for porous host impregnation followed by a reduction step $\left(\mathrm{H}_{2}, \mathrm{NaBH}_{4}\right.$, etc. $)$ at different temperatures depending on the reducing agent (Narehood et al., 2009; Zlotea et al., 2010b, 2015b; Essinger-Hileman et al., 2011). For pure $\mathrm{Pd}$ and $\mathrm{Rh}$ nanoparticles, the use of high temperature, typically 
above $300^{\circ} \mathrm{C}$, as well as high metal loadings usually induces the growth of nanoparticles size and the increase of the particle size distribution (Zhao et al., 2012; Bastide et al., 2013; Zlotea et al., 2015b). Therefore, to prepare ultrasmall noble metal-based nanoparticles, low temperatures for the reduction step, moderate metal loadings, and highly porous supports are preferred.

\section{Characterization of Physicochemical Properties}

Besides the synthesis, the characterization of physicochemical properties of ultrasmall nanoparticles is also challenging. The most encountered difficulties are related to the observation of the crystalline structure by X-ray diffraction (XRD) together with the nanostructure, morphology, and dispersion on the porous support by transmission electron microscopy (TEM).

Light metal ultrasmall nanoparticles, such as $\mathrm{MgH}_{2}$, have too short coherence lengths to diffract X-ray. The XRD patterns of the composites, containing $\mathrm{MgH}_{2}$ nanoparticles with the average sizes of 1.3 and $3.0 \mathrm{~nm}$, do not show any diffraction peaks from the expected $\mathrm{MgH}_{2}$ tetragonal phase [see Figure 1 in Zlotea et al. (2015a)]. The patterns are very similar to the amorphous carbon diffractogram despite large $\mathrm{Mg}$ loading up to $25 \mathrm{wt} \%$.

For noble metals, such as ultrasmall $\mathrm{Pd}$ and $\mathrm{Rh}$ nanoparticles, the XRD patterns clearly show the presence of broad diffraction peaks originating from the $f c c$ structure (Zlotea et al., 2010b, 2015b). Contrary to light metal case, the photons are strongly scattered on the electron clouds of heavy elements and can diffract X-ray, despite their small size. The XRD measurements can be done either in air or under inert atmosphere to avoid surface oxidation during exposure to air.

Additionally, the classical TEM technique is very demanding for air sensitive nanoparticles that may also need cryogenic temperature measurements to avoid beam damage. For $\mathrm{MgH}_{2}$ ultrasmall nanoparticles, the contrast with the carbon support is weak and therefore their size and dispersion can only be visible in dark-field TEM imaging. This is not the case for noble metal nanoparticles that can be noticed in bright-field TEM imaging.

\section{Characterization of Hydrogen Absorption}

The characterization of hydrogen absorption in ultrasmall nanoparticles is complex due to important size effects (Zlotea and Latroche, 2013). The most commonly employed laboratory techniques to measure hydrogen sorption properties are isothermal kinetics, pressure-composition isotherms (PCI), differential scanning calorimetry (DSC), thermo-gravimetric analysis (TGA), and thermo-desorption spectroscopy (TDS). Several examples about size effect on the hydrogen absorption kinetics, thermodynamics, and capacity will be detailed below together with the most encountered difficulties at experimental level.

The kinetic modifications due to nanosizing are generally easy to notice by comparison to bulk counterpart if appropriate methodologies are used (TDS, TGA, isothermal kinetic curves, etc.) (Moretto et al., 2013). As a general trend, the nanosizing strongly improves the hydrogen absorption and desorption kinetics of nanoparticles due to shorter diffusion paths of hydrogen within the nanoparticles and large surface area that increases the reaction rate of all surface-related phenomena (hydrogen dissociation and recombination) (Langhammer et al., 2010; Zlotea and Latroche, 2013). For example, the onset temperature of hydrogen desorption for ultrasmall $\mathrm{MgH}_{2}$ nanoparticles $(\sim 1.3 \mathrm{~nm})$ occurs at a temperature about $245^{\circ} \mathrm{C}$ lower than the microcrystalline material (Zlotea et al., 2015a). Similar trend is also observed for Pd nanoparticles $(\sim 2.5 \mathrm{~nm})$ that desorb hydrogen at around $50^{\circ} \mathrm{C}$ lower temperature than bulk material (Zlotea et al., 2010b).

As it concerns the changes in the thermodynamics, usually PCI and DSC measurements are employed for monitoring size effects. It is well known that phase transition in nanoscaled materials are no longer sharp, as usually observed for bulk (Roduner, 2006). Phase transitions are collective phenomena; therefore, they became less defined in small clusters. As a consequence, DSC measurements show almost vanishing peak transition with decreasing particle size to several nanometers. Indeed, the DSC peak corresponding to the hydrogen desorption from $\mathrm{MgH}_{2}$ nanoparticles with $\sim 3 \mathrm{~nm}$ became more shallow, as compared with bulk counterpart, and completely vanishes for $\sim 1.3 \mathrm{~nm} \mathrm{MgH}_{2}$ clusters (Zlotea et al., 2015a). Nevertheless, the transition from hydride to metal phase (during hydrogen desorption) occurs at lower temperature compared with bulk with a strong size dependence, as expected for nanosized systems that may obey the inverse size scaling law (Roduner, 2006). From our previous reports on $\mathrm{MgH}_{2}$, thermodynamic changes induced by nanosizing are difficult to assess due to important coalescence of nanoparticles observed during PCI measurements at high temperature (around $300^{\circ} \mathrm{C}$ ) (Zlotea et al., 2013). This is due to significant mobility of light $\mathrm{Mg}$ atoms in $\mathrm{Mg} / \mathrm{MgH}_{2}$ nanoparticles at high temperature, whereas $\mathrm{Mg}$ possesses lower diffusivity when alloyed with heavier metal $(\mathrm{Ni})$ in the nanoscaled phase $\mathrm{Mg}_{2} \mathrm{Ni}$. This may be understood in terms of weight of involved elements, since the diffusion rate is proportional to the inverse of squared mass of species.

When PCI curves can be measured without coalescence of nanoparticles (noble metal-based clusters), a typical example of size effect is the sloping of plateau in the PCI curves. It is well known that the plateau pressure (indicating the formation of a hydride phase) becomes steeper with decreasing the particle size of Pd (Sachs et al., 2001; Pundt and Kirchheim, 2006). Several explanations have been proposed, such as size-related changes in surface tension, interface stress due to stabilizers/ scaffolds, or structural heterogeneities of the particles (Pundt and Kirchheim, 2006; Yamauchi et al., 2008). An important decrease of the enthalpy of hydride formation was earlier proposed for $\mathrm{Pd}$ nanoparticles with size around $2.6 \mathrm{~nm}$ (Yamauchi et al., 2008). Moreover, a narrowing of the two-phase regions of solid solution and hydride phases and a decrease in the critical temperature of the two-phase state have been reported for ultrasmall Pd nanoparticles (Yamauchi et al., 2008; Narehood et al., 2009). Nanosizing to ultrasmall dimensions even suppresses the hydride formation, as we recently proven for the supported nanoalloy $\mathrm{Pd}_{90} \mathrm{Co}_{10} \sim 2.4 \mathrm{~nm}$, as compared with the bulk alloy counterpart 
that forms a hydride phase at ambient pressure and temperature conditions (Zlotea et al., 2015c).

We recently reported a significant change in $\mathrm{Rh}-\mathrm{H}$ thermodynamics induced by nanosize: $\mathrm{Rh}$ nanoparticles $<2.3 \mathrm{~nm}$ can absorb hydrogen forming a hydride phase below 1 bar unlike bulk metal that needs $40 \mathrm{kbar}$ hydrogen pressure to form a hydride phase at room temperature (Zlotea et al., 2015b). Rh nanoparticles with sizes $\geq 3 \mathrm{~nm}$ only form solid solutions with hydrogen under similar conditions.

Hydrogen absorption induced by nanosizing was also recently reported for another noble metal (Ir) that usually needs extremely high hydrogen pressure [several tens of kbar (Driessen et al., 1990)] to form a hydride phase. At nanoscale, ultrasmall Ir particles $(\sim 1.5 \mathrm{~nm})$ can absorb large amount of hydrogen at ambient temperature and pressure (Kobayashi et al., 2012a; Zlotea et al., 2014). However, our experimental results point out to the formation of solid solutions with large hydrogen solubility (Zlotea et al., 2014) rather than a hydride phase, as previously claimed (Kobayashi et al., 2012a).

The size effect on the hydrogen storage capacity is not straightforward since it is strongly dependent on the induced thermodynamic changes. For noble metal nanoparticles, downsizing the metal particle size below $3 \mathrm{~nm}$ can be either beneficial or detrimental for the hydrogen sorption properties. The capacity of ultrasmall Rh and Ir nanoparticles noticeably increases, as compared with bulk at ambient pressure and temperature conditions due to thermodynamic changes, as discussed before. On the contrary, nanosizing Pd nanoparticles strongly decrease the hydrogen sorption capacity of the hydride phase from 0.7 to around $0.3 \mathrm{H} / \mathrm{Pd}$ and from bulk to $2 \mathrm{~nm}$ particles at ambient pressure and temperature conditions (Sachs et al., 2001; Pundt and Kirchheim, 2006; Yamauchi et al., 2008).

\section{ULTRASMALL Pd-Rh NANOALLOYS}

The second part will report original results obtained for carbonsupported ultrasmall $\mathrm{Pd}-\mathrm{Rh}$ nanoalloys in the whole binary chemical composition range. The bulk Pd-Rh alloys have been already investigated for their interesting hydrogen storage performances as well as their promising catalytic properties as three-way converters in the exhaust pipes of gasoline-powered engines (Noh et al., 1991, 1993; Cappillino et al., 2014). However, very few studies have reported the effect of nanosizing on the hydrogen storage properties of these materials (Kobayashi et al., 2012b).

\section{Materials and Methods Synthesis}

The synthesis of ultrasmall $\mathrm{Pd}-\mathrm{Rh}$ nanoalloys is based on the incipient wetness impregnation method: a mesoporous carbon host was prepared by a soft template route, as described elsewhere (Zlotea et al., 2015c), followed by impregnation with an aqueous solution of a mixture of metal precursors $\left(\mathrm{RhCl}_{3} \cdot x \mathrm{H}_{2} \mathrm{O}\right.$ and $\mathrm{H}_{2} \mathrm{PdCl}_{4}$ ) and subsequently reduced under $\mathrm{Ar} / \mathrm{H}_{2}$ flow at $300^{\circ} \mathrm{C}$ for $1 \mathrm{~h}$. More details on the synthetic part of composites are given in our previous study (Oumellal et al., 2016). Five compositions have been synthesized in the whole binary composition: $\mathrm{Pd}_{90} \mathrm{Rh}_{10}$, $\mathrm{Pd}_{75} \mathrm{Rh}_{25}, \mathrm{Pd}_{50} \mathrm{Rh}_{50}, \mathrm{Pd}_{25} \mathrm{Rh}_{75}$, and $\mathrm{Pd}_{10} \mathrm{Rh}_{90}$. The final metal composition is $10 \mathrm{wt} \%$ over the whole composite mass.

\section{Hydrogen Sorption Measurements}

Hydrogen sorption properties were determined by measuring the PCI at $20^{\circ} \mathrm{C}$ up to 1 bar of hydrogen pressure using an automated volumetric device (Autosorb IQ Quantachrome). Prior to any sorption measurement, the samples were treated under hydrogen atmosphere at $20^{\circ} \mathrm{C}$ to reduce the oxide layer at the surface of nanoparticles and subsequently degassed at $120^{\circ} \mathrm{C}$ to remove water molecules formed during this step (Ghimbeu et al., 2011). The hydrogen absorption/desorption is completely reversible for all samples. The hydrogen sorption capacity is expressed in wt $\%$ over the entire mass of sample.

\section{X-Ray Diffraction}

Structural characterizations were performed by XRD using a Bruker D8 Advance instrument $\left(\mathrm{Cu}-\mathrm{K}_{\alpha}\right.$, Bragg-Brentano geometry, Anton Paar chamber TTK450, and Våntec Position Sensitive Detector). In situ XRD measurements were performed under dynamic vacuum and 1 bar of hydrogen pressures at room temperature. The XRD patterns have been analyzed by the TOPAS software (Bruker AXS Topas 4.2) to determine the lattice parameters.

\section{Transmission Electron Microscopy}

The micro(nano)structural observations were performed by TEM with a $200-\mathrm{kV}$ FEG TEM (FEI Tecnai F20 equipped with a Gatan energy Imaging Filter, resolution $0.24 \mathrm{~nm}$ ). The nanoparticle size distribution and average size have been determined by statistical analyzes of several TEM images.

\section{X-Ray Absorption Spectroscopy}

The local structure of the $\mathrm{Pd}-\mathrm{Rh}$ nanoalloys was investigated by $\mathrm{X}$-ray absorption spectroscopy (XAS) in transmission mode on ROCK beam line at the SOLEIL synchrotron. The X-ray absorption spectra at the $\mathrm{K}$ edges of $\mathrm{Pd}$ and $\mathrm{Rh}$ were measured under $\mathrm{H}_{2}$ and $\mathrm{N}_{2}$ flow $(30 \mathrm{ml} / \mathrm{min}$ ) at room temperature with a typical edge jump between 0.4 and 0.8 . Bulk Pd and Rh were also measured and used as references. The powder samples were placed inside the Lytle-type cell available on the beam line (Fontaine et al., 2013). The sample cell was connected to a gas distribution system that allows careful control of the gas mixture and the flow at atmospheric pressure. The samples were pretreated under hydrogen flow at room temperature to reduce the oxide layer at the surface of nanoparticles (Ghimbeu et al., 2011). The XAS data treatment and EXAFS refinements were performed by the help of the MAX program package $\left(E_{0}=24,350\right.$ and $23,230 \mathrm{eV}$ for $\mathrm{Pd}$ and Rh K edges, respectively, Fourier transform range 4-14 $\AA^{-1}$ ) (Michalowicz et al., 2009, 2013). EXAFS fit was performed on first-sphere filtered spectra. Theoretical phases and amplitudes were computed with FEFF8 on the basis of Pd and Rh metal $f c c$ structures (Ankudinov et al., 1998, 2003). Due to the close proximity of Rh and Pd in the periodic table and their similar atomic radius, it was not possible to distinguish $\mathrm{Pd}$ and $\mathrm{Rh}$ first neighbors 
$(\mathrm{NN})$, and we have used a unique $(\mathrm{Pd} / \mathrm{Rh})-\mathrm{NN}$ shell. The refined parameters are the coordination number $(N)$, the Debye-Waller factor $\left(\sigma^{2}\right)$, and the distance between the absorbing atom (either $\mathrm{Pd}$ or $\mathrm{Rh}$ ) and the first neighbors $(R)$. The energy shift $\Delta E_{0}$ was refined first for bulk Pd and $\mathrm{Rh}$ references (4.7 and $3.7 \mathrm{eV}$, respectively) and then fixed for further refinements. Statistical errors and error bars were evaluated as recommended by the IXS Standard and Criteria Subcommittee (Sayers, 2000). According to these recommendations, the goodness of fit was evaluated using the reduced $\Delta \chi^{2}$ minimum or quality factor $(\mathrm{QF})$.

\section{RESULTS}

\section{Crystalline Structure and Nanostructure}

The XRD patterns of ultrasmall $\mathrm{Pd}-\mathrm{Rh}$ nanoparticles are shown in Figure 1. Typical TEM images and histograms of particle size for all Pd-Rh nanoalloys are shown in Figure S1 in Supplementary Material. Although the diffraction peaks are very board, XRD investigations prove that these nanoparticles adopt a $f c c$ crystal structure $(F m \overline{3} m)$ typical for Pd-Rh bulk alloys (Raub, 1959). The $f c c$ lattice parameter, as obtained from $\mathrm{XRD}$, together with the average particle sizes, as determined by TEM, is listed in Table 1. The lattice parameters vary linearly with the composition, in agreement with bulk $\mathrm{Pd}-\mathrm{Rh}$ alloys (Raub, 1959). This trend is typical for substitutional alloys and proves the formation of $\mathrm{Pd}-\mathrm{Rh}$ nanoalloys in our synthetic conditions. To further confirm the formation of nanoalloys, EDX chemical analysis has been carried out for two samples: $\mathrm{Pd}_{75} \mathrm{Rh}_{25}$ and $\mathrm{Pd}_{50} \mathrm{Rh}_{50}$ (Figures S2 and S3 in Supplementary Material). From these analyzes, $\mathrm{Pd}$ and $\mathrm{Rh}$ are uniformly distributed on the carbon support and coexist within the same nanoparticles in both selected compositions. Quantitative EDX analysis for the $\mathrm{Pd}_{50} \mathrm{Rh}_{50}$ sample is very close to the nominal 50:50 with a dispersion of around 11 at $\%$. These results confirm our claim of Pd-Rh nanoalloy formation. The TEM average particle sizes are between
1.5 and $3.0 \mathrm{~nm}$ thus, within our definition, these nanoalloys are ultrasmall nanoparticles.

\section{Hydrogen Absorption}

The hydrogen adsorption properties of $\mathrm{Pd}-\mathrm{Rh}$ nanoalloys have been studied by volumetric method (PCI curves), in situ XRD and EXAFS. DSC analysis was unsuccessful for studying the hydrogen sorption in these nanomaterials due to issues discussed above (see Characterization of Hydrogen Absorption). The PCI curves measured up to 1 bar $\mathrm{H}_{2}$ pressure and $20^{\circ} \mathrm{C}$ for all $\mathrm{Pd}-\mathrm{Rh}$ composites and pristine carbon are plotted in Figure 2. For the sake of comparison, the PCI curve of pure Pd ultrasmall nanoparticles (average size $\sim 2.5 \mathrm{~nm}$ ) is also given. Interestingly, the hydrogen uptake of $\mathrm{Pd}_{90} \mathrm{Rh}_{10}$ nanoalloy around 1 bar $\mathrm{H}_{2}$ pressure is very close to the value of pure $\mathrm{Pd}$. The hydrogen adsorption capacity of pristine carbon is very small, in agreement with our previous report (Zlotea et al., 2015c). The hydrogen uptake increases in the presence of $\mathrm{Pd}-\mathrm{Rh}$ nanoparticles with the highest enhancement for Pd-rich compositions, despite the increase of the weight of final composites relative to pristine carbon. This might be due to adsorption of molecular $\mathrm{H}_{2}$ on the developed surfaces of ultrasmall nanoparticles and adsorption in nanoalloys (formation of solid solutions and/or hydride phase). However, the formation

TABLE 1 | Lattice parameter, as obtained from XRD, and average particle size, as determined by TEM.

\begin{tabular}{lcc}
\hline Sample & Lattice parameter $(\mathbf{A})$ & Average particle size by TEM (nm) \\
\hline Bulk Pd & 3.891 & - \\
$\mathrm{Pd}_{90} \mathrm{Rh}_{10}$ & $3.89(1)$ & $1.4(3)$ \\
$\mathrm{Pd}_{75} \mathrm{Rh}_{25}$ & $3.87(1)$ & $2.0(6)$ \\
$\mathrm{Pd}_{50} \mathrm{Rh}_{50}$ & $3.85(1)$ & $1.8(6)$ \\
$\mathrm{Pd}_{25} \mathrm{Rh}_{75}$ & $3.83(1)$ & $2.0(7)$ \\
$\mathrm{Pd}_{10} R h_{90}$ & $3.81(1)$ & $3.0(1.0)$ \\
Bulk Rh & 3.80 & -
\end{tabular}

For comparison purposes, the parameters from bulk $P d$ and $R h$ are also listed, as taken from Raub (1959) and Noh et al. (1993).



FIGURE 1 | XRD patterns of supported Pd-Rh ultrasmall nanoalloys (reduced at $300^{\circ} \mathrm{C}$ ) with the following compositions: $\mathbf{P d}_{90} \mathbf{R h}_{10}$, $\mathrm{Pd}_{75} \mathrm{Rh}_{25}, \mathrm{Pd}_{50} \mathrm{Rh}_{50}, \mathrm{Pd}_{25} \mathrm{Rh}_{75}$, and $\mathbf{P d}_{10} \mathrm{Rh}_{90}$.

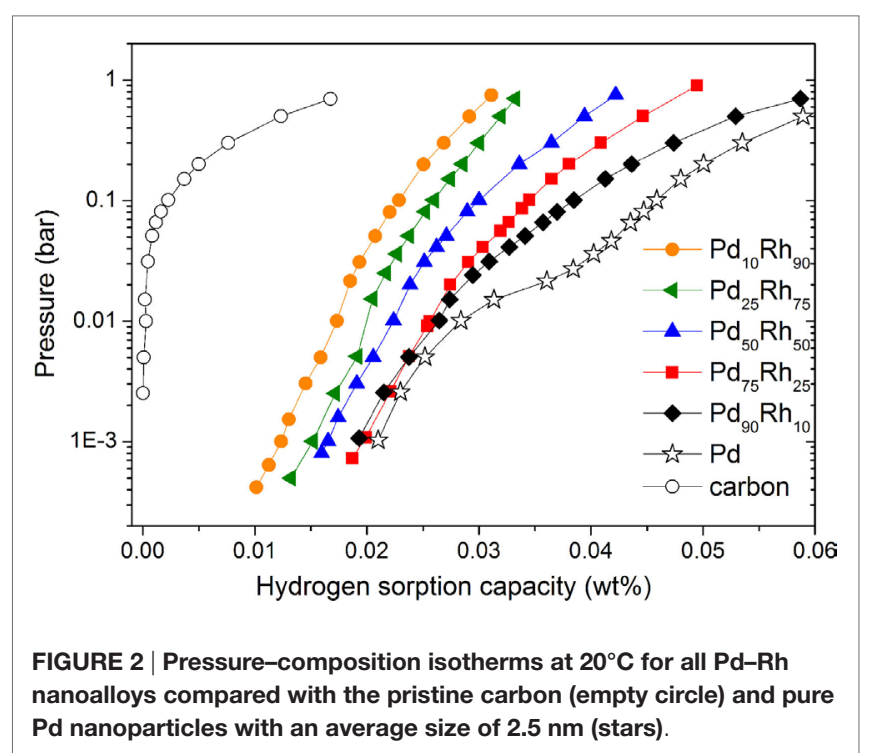


of hydride phases in these nanoalloys can be excluded due to the absence of equilibrium plateau pressure in the PCI curves, in contrast with pure Pd ultrasmall particles that show a slopped plateau pressure at around 0.02 bar. Despite the presence of an inflection point in the PCI curves of the Pd-rich compositions $\left(\mathrm{Pd}_{90} \mathrm{Rh}_{10}\right.$, $\mathrm{Pd}_{75} \mathrm{Rh}_{25}$, and $\mathrm{Pd}_{50} \mathrm{Rh}_{50}$ ), we can conclude that hydrogen uptake in these nanoalloys can be explained by two main mechanisms: hydrogen adsorption (surface reactions) and absorption (formation of solid solutions). Nevertheless, we cannot clearly discriminate between these reactions only from PCI measurements.

To clarify this question, we have performed in situ XRD for two Pd-rich nanoalloys $\left(\mathrm{Pd}_{90} \mathrm{Rh}_{10}\right.$ and $\left.\mathrm{Pd}_{75} \mathrm{Rh}_{25}\right)$ under vacuum and 1 bar $\mathrm{H}_{2}$ pressure. As noticed in Figure 3, XRD diffraction peaks are very board due to the small nanoparticle sizes, and the most intense peaks (111 and 200) are strongly overlapping, irrespective of the composition and the gaseous environment (vacuum and hydrogen). For the $\mathrm{Pd}_{90} \mathrm{Rh}_{10}$ nanoalloy, a small shift to lower $2 \theta$ angles can be noticed for the (111), (220), and (311) peaks confirming hydrogen absorption. Hydrogen atoms are randomly occupying the interstitial sites of the $f c c$ structure, and the lattice cell volume is expanding upon absorption. Indeed, the lattice parameter, as refined by the TOPAS software, increases from 3.89 (1) to 3.94 (1) $\AA$ under 1 bar $\mathrm{H}_{2}$ pressure at $20^{\circ} \mathrm{C}$. On the contrary, for the $\mathrm{Pd}_{75} \mathrm{Rh}_{25}$ nanoalloy peak displacement is difficult to notice, despite similar PCI curves. Therefore, in situ XRD confirms the hydrogen absorption and formation of solid solutions with hydrogen only for the Pd-richest nanoalloy $\left(\mathrm{Pd}_{90} \mathrm{Rh}_{10}\right)$.

To further discriminate between surface-related reactions and absorption in $\mathrm{Pd}_{75} \mathrm{Rh}_{25}, \mathrm{Pd}_{50} \mathrm{Rh}_{50}$, and $\mathrm{Pd}_{25} \mathrm{Rh}_{75}$ nanoalloys, we have carried out in-depth XAS characterization at synchrotron. XAS spectra at the Pd and $\mathrm{Rh} \mathrm{K}$ edges have been recorded for $\mathrm{Pd}_{75} \mathrm{Rh}_{25}, \mathrm{Pd}_{50} \mathrm{Rh}_{50}$, and $\mathrm{Pd}_{25} \mathrm{Rh}_{75}$ nanoalloys under $\mathrm{N}_{2}$ and $\mathrm{H}_{2}$ flow at $20^{\circ} \mathrm{C}$. The XANES regions show negligible shift, irrespective of the composition and gas atmosphere (Figures S4 and S5 in Supplementary Material).

EXAFS spectra at Pd K edge and corresponding module of the Fourier transform of $\mathrm{Pd}_{75} \mathrm{Rh}_{25}, \mathrm{Pd}_{50} \mathrm{Rh}_{50}$, and $\mathrm{Pd}_{25} \mathrm{Rh}_{75}$ nanoalloys under $\mathrm{N}_{2}$ and $\mathrm{H}_{2}$ are shown in Figure 4. From EXAFS oscillations at $\mathrm{Pd} \mathrm{K}$ edge, the $\mathrm{Pd}$ atoms environment of the $\mathrm{Pd}-\mathrm{Rh}$ nanoalloys depends on the gas atmosphere with the strongest effect for $\mathrm{Pd}_{75} \mathrm{Rh}_{25}$. EXAFS spectra at Rh K edge are shown in Figure S6 in Supplementary Material. Contrary to Pd K edge, EXAFS spectra at Rh K edge are very similar, irrespective of composition and gas environment (Figure S6 in Supplementary Material). The results of EXAFS refinements for the first shell of $\mathrm{Pd}_{25} \mathrm{Rh}_{75}, \mathrm{Pd}_{50} \mathrm{Rh}_{50}$, and $\mathrm{Pd}_{75} \mathrm{Rh}_{25}$ nanoalloys are listed in Table 2 .

At $\mathrm{Rh} \mathrm{K}$ edge, the coordination number $N$ is around 9-10, whereas at $\mathrm{Pd} \mathrm{K}$ edge $N$ is in between 6 and 8 . The decrease of $N$ can be understood by an increased number of dangling bonds due to the large fraction of surface atoms in small clusters (Frenkel et al., 2001; Evans and Tromp, 2008). However, for substitutional alloys, as suggested by XRD, this decrease should affect in the same way $N$ at both Pd and Rh edges. Since $N$ at Pd $\mathrm{K}$ edge is smaller than the one at $\mathrm{Rh} \mathrm{K}$ edge, the local structure of nanoalloys is suggested to be composed of partially segregated Pd-rich surface and Rh-rich core. Similar partial surface segregation of Pd was already proposed for the carbon-supported $\mathrm{Pd}-\mathrm{Rh}$ alloys with larger nanoparticle size (Oumellal et al. submitted) ${ }^{1}$.

At $\mathrm{Rh} \mathrm{K}$ edge, there are no obvious changes in the Rh-NN distance (2.67-8 $\AA$ ) and Debye-Waller factor $\left(\sigma^{2}=0.006-7 \AA^{2}\right)$, whatever the composition and the atmosphere. At Pd K edge, the Debye-Waller factor under inert gas increases from bulk to nanoparticles (from 0.006 to $0.010 \AA^{2}$, respectively), in agreement with previous studies (Frenkel et al., 2001; Zlotea et al., 2010b). This can be understood in terms of an increase of the static disorder in nanoparticles due to the relaxation of bond lengths at the surface undergoing substantial strain.

The EXAFS results at Pd K edge of Pd-Rh nanoalloys under $\mathrm{H}_{2}$ atmosphere reveal important modifications. In Figure 4, the positions of the main FT peak of $\mathrm{Pd}_{75} \mathrm{Rh}_{25}$ and $\mathrm{Pd}_{50} \mathrm{Rh}_{50}$ nanoalloys under $\mathrm{H}_{2}$ are slightly shifted to larger distances, as compared

${ }^{1}$ Oumellal, Y., Provost, K., Ghimbeu, C. M., Martinez de Yuso, A., and Zlotea, C. (2016). Tailoring hydrogen sorption properties of Pd-Rh nanoalloys (submitted).
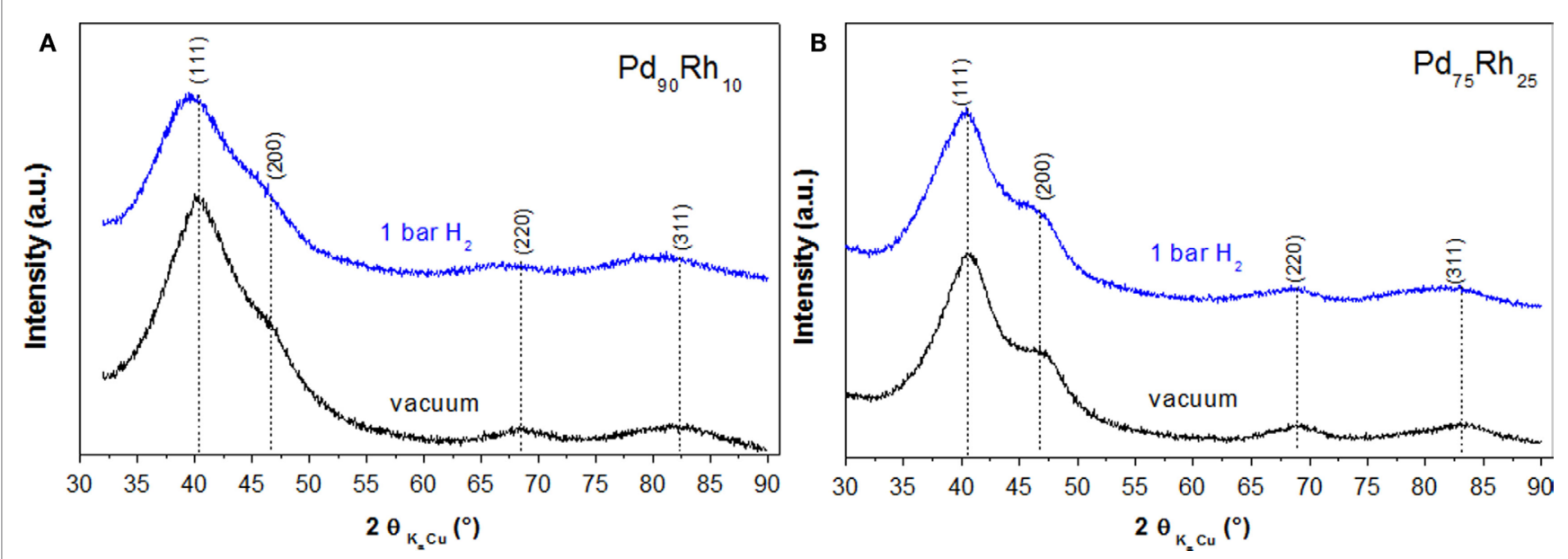

FIGURE 3 | In situ XRD for $\mathrm{Pd}_{90} \mathrm{Rh}_{10}$ (A) and $\mathrm{Pd}_{75} \mathrm{Rh}_{25}$ (B) nanoalloys under vacuum (black) and 1 bar $\mathrm{H}_{2}$ pressure (blue) at $20^{\circ} \mathrm{C}$ 



FIGURE 4 | Experimental EXAFS spectra at Pd K edge and corresponding module of the Fourier transform of $\mathrm{Pd}_{75} \mathrm{Rh}_{25}(\mathrm{~A}, \mathrm{~B}), \mathrm{Pd}_{50} \mathrm{Rh}_{50}(\mathrm{C}, \mathrm{D})$, and $\mathbf{P d}_{25} \mathbf{R h}_{75}(\mathrm{E}, \mathrm{F})$ under $\mathbf{N}_{2}$ (black) and $\mathbf{H}_{2}$ (red) at room temperature. The dotted lines indicate the positions of the main $\mathrm{FT}$ peaks.

with the nanoalloys under inert gas. Indeed, an expansion of the $R_{\text {Pd-NN }}$ distances is noticed for $\mathrm{Pd}_{75} \mathrm{Rh}_{25}$ and $\mathrm{Pd}_{50} \mathrm{Rh}_{50}$ under $\mathrm{H}_{2}$ gas: $\Delta R=0.03$ and $0.02 \AA$, respectively (Table 2). Moreover, since the $R_{\mathrm{Rh}-\mathrm{NN}}$ is not affected by the gas environment, this observation suggests that hydrogen atoms preferentially occupy the interstitial sites in the Pd-rich domains. This finding undoubtedly indicates the occurrence of hydrogen absorption in these ultrasmall nanoparticles and formation of solid solutions with hydrogen. We recall that this conclusion was impossible to state only from PCI and in situ XRD measurements. For the Rh-rich nanoalloy 
TABLE 2 | Results of EXAFS refinements for the first shell of supported Pd-Rh nanoalloys under different gaseous environments at $20^{\circ} \mathrm{C}$ : coordination number $(N)$, Debye-Waller factor $\left(\sigma^{2}\right)$, nearest neighbor distance $(R)$, and the quality of fit (QF).

\begin{tabular}{|c|c|c|c|c|c|c|c|c|c|c|}
\hline \multirow[t]{2}{*}{ Sample } & \multirow[t]{2}{*}{ Size (nm) } & \multirow[t]{2}{*}{ Gas } & \multicolumn{4}{|c|}{ Pd K edge } & \multicolumn{4}{|c|}{ Rh K edge } \\
\hline & & & $N$ & $\sigma^{2}\left(\AA^{2}\right)$ & $\boldsymbol{R}_{\mathrm{Pd}-\mathrm{NN}}(\AA)$ & QF & $N$ & $\sigma^{2}\left(\AA^{2}\right)$ & $\boldsymbol{R}_{\mathrm{Rh}-\mathrm{NN}}(\AA)$ & QF \\
\hline \multirow[t]{2}{*}{$\mathrm{Pd}$} & Bulk & Air & 12 & $0.006(1)$ & $2.76(1)$ & 4.5 & - & - & - & - \\
\hline & & $\mathrm{H}_{2}^{\mathrm{a}}$ & $12^{a}$ & $0.008(1)^{a}$ & $2.84(1)^{\mathrm{a}}$ & - & - & - & - & - \\
\hline $\mathrm{Rh}$ & Bulk & Air & - & - & - & - & 12 & $0.006(1)$ & $2.69(1)$ & 3.3 \\
\hline \multirow[t]{2}{*}{$\mathrm{Pd}_{75} \mathrm{Rh}_{25}$} & 2.0 & $\mathrm{~N}_{2}$ & $7.6(1.1)$ & $0.009(1)$ & $2.75(1)$ & 0.6 & $10(0.9)$ & $0.006(1)$ & $2.68(1)$ & 1.6 \\
\hline & & $\mathrm{H}_{2}$ & $7.8(1.6)$ & $0.010(1)$ & $2.78(1)$ & 1.0 & $9(0.9)$ & 0.007 (1) & $2.68(1)$ & 0.6 \\
\hline \multirow[t]{2}{*}{$\mathrm{Pd}_{50} \mathrm{Rh}_{50}$} & 1.8 & $\mathrm{~N}_{2}$ & $6.1(1.3)$ & $0.010(1)$ & $2.74(1)$ & 0.6 & $8.8(0.6)$ & $0.006(1)$ & $2.68(1)$ & 0.1 \\
\hline & & $\mathrm{H}_{2}$ & $7.0(1.4)$ & $0.011(1)$ & $2.76(1)$ & 0.3 & $8.9(0.7)$ & $0.006(1)$ & $2.68(1)$ & 4.5 \\
\hline \multirow[t]{2}{*}{$\mathrm{Pd}_{25} \mathrm{Rh}_{75}$} & 2.0 & $\mathrm{~N}_{2}$ & $6.1(1.2)$ & 0.009 (1) & $2.73(1)$ & 0.5 & $9.5(0.4)$ & $0.006(1)$ & 2.67 (1) & 5.4 \\
\hline & & $\mathrm{H}_{2}$ & $6(1.2)$ & $0.010(1)$ & $2.74(1)$ & 0.3 & $9.4(0.6)$ & $0.006(1)$ & $2.68(1)$ & 5.6 \\
\hline
\end{tabular}

${ }^{a}$ Results for bulk $\mathrm{Pd}$ under $\mathrm{H}_{2}$ are also given for comparison from Zlotea et al. (2010b).

studied by EXAFS, the difference between $R_{\mathrm{Pd}-\mathrm{NN}}$ distances under $\mathrm{N}_{2}$ and $\mathrm{H}_{2}$ gas is within the error bar. Thus, hydrogen adsorption on the developed surface area might account for hydrogen uptake in ultrasmall $\mathrm{Rh}$-rich nanoalloys $\left(\mathrm{Pd}_{25} \mathrm{Rh}_{75}\right.$ and $\left.\mathrm{Pd}_{10} \mathrm{Rh}_{90}\right)$, whereas both hydrogen adsorption and absorption (with formation of solid solutions) can explain the hydrogen uptake in Pd-rich nanoalloys $\left(\mathrm{Pd}_{90} \mathrm{Rh}_{10}, \mathrm{Pd}_{75} \mathrm{Rh}_{25}\right.$, and $\left.\mathrm{Pd}_{50} \mathrm{Rh}_{50}\right)$.

\section{DISCUSSION}

The lattice parameters of $\mathrm{Pd}-\mathrm{Rh}$ nanoparticles, as determined by $\mathrm{XRD}$, vary linearly with the composition (Table 1), as expected for substitutional alloys. The synthetic temperature $\left(300^{\circ} \mathrm{C}\right)$ is much lower than the critical temperature of the miscibility gap reported in the bulk $\mathrm{Pd}-\mathrm{Rh}$ phase diagram $\left(850^{\circ} \mathrm{C}\right)$. Thus, these carbon-supported nanoalloys are considered as metastable phases kinetically stabilized in the present synthetic conditions. More discussion about thermodynamic aspects and stability of these phases at nanoscale are detailed in our previous study (Oumellal et al., 2016). As it concerns the local structure of $\mathrm{Pd}-\mathrm{Rh}$ nanoalloys, EXAFS investigations at both $\mathrm{Rh}$ and $\mathrm{Pd} \mathrm{K}$ edges under inert atmosphere have uncovered a partially segregated structure with Pd-rich surface and Rh-rich core within the nanoparticles.

From PCI investigations (Figure 2), none of Pd-Rh ultrasmall nanoalloys forms a hydride phase under the present conditions (absence of plateau pressure). Interestingly, the composites have higher hydrogen sorption capacities than the pristine carbon despite the increase of weight by insertion of nanoparticles with the most important enhancement for Pd-rich nanoalloys. Both hydrogen adsorption on the surface of nanoalloys and absorption inside the volume of nanoparticles (formation of solid solutions) can account for the enhanced capacities of nanoalloys. However, we cannot discriminate between surface and volume reactions only from PCI measurements. In situ XRD under vacuum and 1 bar $\mathrm{H}_{2}$ pressure provides more information about the hydrogen absorption in the Pd-rich compositions (Figure 3). It is clear that hydrogen absorption and subsequent formation of solid solutions in $\mathrm{Pd}_{90} \mathrm{Rh}_{10}$ nanoalloy occur at 1 bar and $20^{\circ} \mathrm{C}$. On the contrary, no concluding results could be obtained regarding hydrogen absorption in the $\mathrm{Pd}_{75} \mathrm{Rh}_{25}$ nanoalloy from in situ XRD. The final proof of hydrogen absorption and formation of solid solutions in both $\mathrm{Pd}_{75} \mathrm{Rh}_{25}$ and $\mathrm{Pd}_{50} \mathrm{Rh}_{50}$ nanoalloys was brought by in situ EXAFS. Moreover, the latter investigations suggest that hydrogen atoms preferentially occupy the interstitial sites in the Pd-rich domains of these nanoalloys. This is in agreement with the previous report on microsegregation in Pd-rich alloys with $\mathrm{Rh}$ induced by hydride formation (Noh et al., 1991).

The chemical composition and the decrease of particle size of $\mathrm{Pd}-\mathrm{Rh}$ nanoalloys to ultrasmall dimension have drastic consequences on the hydrogen sorption properties. The increase of $\mathrm{Rh}$ content in bulk Pd-Rh alloys (maximum 25 at \% of Rh) strongly influences the thermodynamic properties of the hydride formation: the enthalpies of hydride formation $\left(-\Delta H_{\text {hydride }}\right)$ are 37,30 , and $19.4 \mathrm{~kJ} / \mathrm{molH}_{2}$ for pure $\mathrm{Pd}, \mathrm{Pd}_{90} \mathrm{Rh}_{10}$, and $\mathrm{Pd}_{75} \mathrm{Rh}_{25}$ alloys, respectively (Noh et al., 1993). This indicates an increase of the equilibrium pressure of hydride formation from $0.022,0.480$ to 28.3 bar at room temperature $\left(25^{\circ} \mathrm{C}\right)$ for pure $\mathrm{Pd}, \mathrm{Pd}_{90} \mathrm{Rh}_{10}$, and $\mathrm{Pd}_{75} \mathrm{Rh}_{25}$ alloys, respectively (Noh et al., 1993; Cappillino et al., 2014). Our recent study on $\mathrm{Pd}-\mathrm{Rh}$ nanoalloys with large average size (5-6 nm) showed less important thermodynamic changes for the same compositions (See footnote text 1). The values of enthalpy of hydride formation $\left(-\Delta H_{\text {hydride }}\right)$ are 35 and $30 \mathrm{~kJ} /$ $\mathrm{molH}_{2}$ for $\mathrm{Pd}_{90} \mathrm{Rh}_{10}$ (average size $6.4 \mathrm{~nm}$ ) and $\mathrm{Pd}_{75} \mathrm{Rh}_{25}$ (average size $5.5 \mathrm{~nm}$ ) nanoalloys, respectively. Therefore, the values of the equilibrium plateau pressure of hydride formation correspond to 0.041 and 1.0 bar at room temperature for the $\mathrm{Pd}_{90} \mathrm{Rh}_{10}$ and $\mathrm{Pd}_{75} \mathrm{Rh}_{25}$ nanoalloys, respectively. Consequently, these nanoalloys with average size around 5-6 $\mathrm{nm}$ can form hydride phases under ambient conditions. The destabilization of hydride formation by alloying with $\mathrm{Rh}$ is smaller in nanosized $\mathrm{Pd}-\mathrm{Rh}$ alloys relative to bulk counterparts. In the present case, decreasing the size of $\mathrm{Pd}-\mathrm{Rh}$ nanoalloys to ultrasmall dimensions $(\leq 3 \mathrm{~nm}$ ) completely suppresses the hydride formation for all compositions. Ultrasmall Pd-rich nanoalloys $\left(\mathrm{Pd}_{90} \mathrm{Rh}_{10}, \mathrm{Pd}_{75} \mathrm{Rh}_{25}\right.$ and $\mathrm{Pd}_{50} \mathrm{Rh}_{50}$ ) only form solid solutions under ambient conditions, as demonstrated by in situ XRD and EXAFS. We hypothesize that the observed hydride suppression in the present Pd-rich nanoparticles might be due to the important stress resulting from their ultrasmall size. 


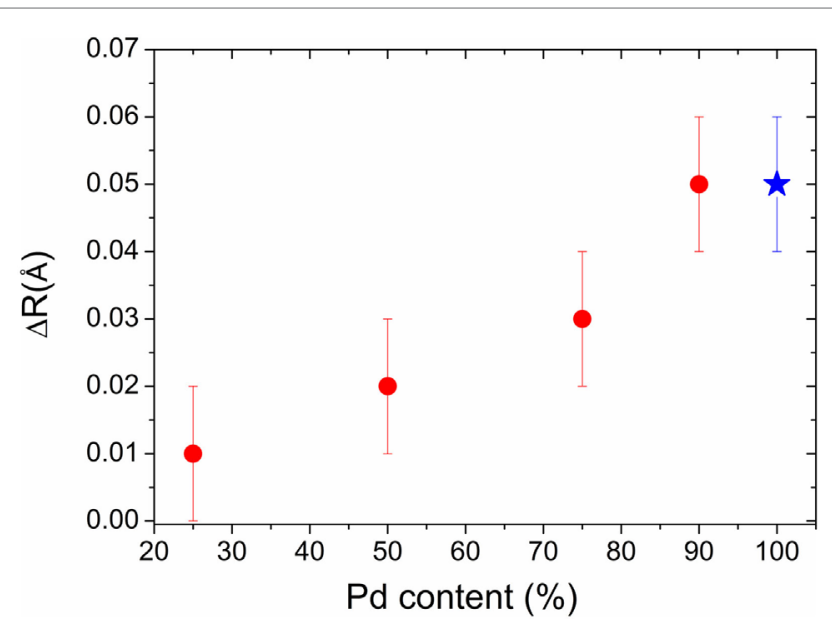

FIGURE 5 | The increase of first neighbors distance $\Delta R$ (red symbols) upon hydrogen absorption at 1 bar $\mathrm{H}_{2}$ pressure and $20^{\circ} \mathrm{C}$ in ultrasmall $\mathbf{P d}-\mathbf{R h}$ nanoalloys versus $\mathbf{P d}$ content. The value for the $\mathrm{Pd}_{90} \mathrm{Rh} \mathrm{h}_{10}$ composition was calculated based on in situ XRD, whereas the ones for $\mathrm{Pd}_{75} \mathrm{Rh}_{25}, \mathrm{Pd}_{50} \mathrm{Rh}_{50}$, and $\mathrm{Pd}_{25} \mathrm{Rh}_{75}$ were determined by in situ EXAFS at $\mathrm{Pd} \mathrm{K}$ edge. For the sake of comparison, our previous result on carbon-supported 2.5-nm Pd nanoparticles is also plotted (blue symbol), as obtained by in situ EXAFS (Zlotea et al., 2010b).

It is obvious that the $\mathrm{Pd}-\mathrm{Rh}$ nanoalloys chemical composition plays an important role for the hydrogen solubility in the solid solutions formed under ambient conditions. Figure 5 shows the evolution of $\Delta R$ (the increase in first neighbors distance upon hydrogen absorption at 1 bar and $20^{\circ} \mathrm{C}$, as calculated based on in situ XRD and EXAFS) as function of Pd content in the ultrasmall Pd-Rh nanoalloys. The change in $\Delta R$ can be directly related to the hydrogen solubility in solid solutions, which is higher for Pd-rich compositions, in agreement with PCI curves (Figure 2). This can be understood in terms of hydrogen preferential occupation in the Pd-rich regions, as suggested by in situ EXAFS. Interestingly, the $\mathrm{Pd}_{90} \mathrm{Rh}_{10}$ nanoalloy can accommodate as much hydrogen-forming solid solutions as pure $\mathrm{Pd}$ nanoparticles $(2.5 \mathrm{~nm})$ forming a hydride phase under similar conditions, in agreement with the PCI curves in Figure 2.

In summary, hydrogen uptake mechanism in ultrasmall Rh-rich nanoalloys $\left(\mathrm{Pd}_{25} \mathrm{Rh}_{75}\right.$ and $\left.\mathrm{Pd}_{10} \mathrm{Rh}_{90}\right)$ is based only on hydrogen adsorption on the developed surface area of nanoparticles, whereas the hydrogen interaction with Pd-rich nanoalloys $\left(\mathrm{Pd}_{90} \mathrm{Rh}_{10}, \mathrm{Pd}_{75} \mathrm{Rh}_{25}\right.$, and $\left.\mathrm{Pd}_{50} \mathrm{Rh}_{50}\right)$ involves both hydrogen adsorption and absorption with formation of solid solutions.

An important aspect of the synthesis and the characterization of such nanomaterials is the coalescence of nanoparticles and formation of large aggregates with bulk-like properties. We have never observed coalescence during repeating measurements/ handling of the present $\mathrm{Pd}-\mathrm{Rh}$ nanoparticles, irrespective of their size and composition. This might be due to the heavy weight of both $\mathrm{Pd}$ and $\mathrm{Rh}$ atoms that possess very low diffusivity at the present temperatures $\left(20-120^{\circ} \mathrm{C}\right)$. This might also explain the formation of metastable phases kinetically stabilized in our synthetic conditions.

\section{CONCLUSION}

In the first part of this work, recent advances on synthesis, characterization and hydrogen absorption properties of ultrasmall nanoparticles (defined here as nanoparticles with average size $\leq 3 \mathrm{~nm}$ ) have been shortly reviewed. The experimental challenges encountered in synthesis, handling, characterization, and accurate determination of hydrogen absorption properties of $\mathrm{MgH}_{2}$ and noble metal-based ultrasmall nanoparticles have been addressed.

The second part reports original results obtained for carbonsupported ultrasmall $\mathrm{Pd}-\mathrm{Rh}$ nanoalloys. We have successfully prepared ultrasmall $\mathrm{Pd}-\mathrm{Rh}$ nanoalloys by liquid impregnation method followed by reduction at $300^{\circ} \mathrm{C}$, despite the large miscibility gap in the bulk $\mathrm{Pd}-\mathrm{Rh}$ phase diagram (with the critical temperature $\sim 850^{\circ} \mathrm{C}$ ). EXAFS investigations suggest that the local structure of these nanoalloys is partially segregated into Rh-rich core and Pd-rich surface.

Downsizing to ultrasmall dimensions induces drastic modifications of hydrogen absorption properties of $\mathrm{Pd}-\mathrm{Rh}$ alloys and completely suppresses the hydride formation for all compositions of ultrasmall nanoparticles, as observed by the PCI measurements at ambient conditions. This finding is in contrast with both bulk alloys and larger sized nanoalloys (5-6 nm): Pd-rich compositions $\left(\mathrm{Pd}_{90} \mathrm{Rh}_{10} \sim 6.4 \mathrm{~nm}\right.$ and $\mathrm{Pd}_{75} \mathrm{Rh}_{25} \sim 5.5 \mathrm{~nm}$ ) form hydride phases under similar conditions. Ultrasmall $\mathrm{Pd}_{90} \mathrm{Rh}_{10}$, $\mathrm{Pd}_{75} \mathrm{Rh}_{25}$, and $\mathrm{Pd}_{50} \mathrm{Rh}_{50}$ nanoalloys absorb hydrogen-forming solid solutions at atmospheric pressure and room temperature. The hydrogen solubility in solid solutions is higher for Pd-rich compositions. This can be understood in terms of hydrogen preferential occupation in the Pd-rich regions, as suggested by in situ EXAFS. The Rh-rich nanoalloys only adsorb hydrogen on the developed surfaces of ultrasmall nanoparticles.

These results have been highlighted by combined laboratory and large-scale facility technique, such as in situ EXAFS. Apart from the Pd-richest composition, common laboratory techniques, such as in situ XRD, DSC, and PCI, could not distinguish between hydrogen adsorption on surface and hydrogen absorption in volume accompanied by formation of solid solutions. Therefore, it is obvious that the rising need for in situ characterization methods provided by large-scale facilities to explore the hydrogen interaction with ultrasmall nanoparticles. This is an important topic of fundamental research not only for solid-state hydrogen storage materials and sensors but also for heterogeneous catalysis, given that ultrasmall Pd-based nanoparticles are widely used for many chemical reactions involving hydrogen.

\section{AUTHOR CONTRIBUTIONS}

$\mathrm{CZ}$ ensured the direction of the research project, performed the XAS experiments and EXAFS refinements, and provided necessary opportunities for fruitful discussion among authors. YO performed the synthesis and characterization of all composite materials and participated to XAS experiments. KP helped for XAS experiments, analysis, and EXAFS refinements. CG carried out the synthesis and the characterization of pristine porous carbon support as well as the EDX chemical mapping for composite materials. 


\section{ACKNOWLEDGMENTS}

Fabrice Couturas is warmly acknowledged for help during in situ XAS experiments at Soleil. The authors thank Julie Bourgon (ICMPE) and Loïc Vidal (IS2M) for TEM measurements.

\section{FUNDING}

The work was funded by the French National Research Agency (ANR) under GENESIS project contract no 13-BS08-0004.

\section{REFERENCES}

Ankudinov, A. L., Nesvizhskii, A. I., and Rehr, J. J. (2003). Dynamic screening effects in x-ray absorption spectra. Phys. Rev. B 67, 115120. doi:10.1103/ PhysRevB.67.115120

Ankudinov, A. L., Ravel, B., Rehr, J. J., and Conradson, S. D. (1998). Real-space multiple-scattering calculation and interpretation of $\mathrm{x}$-ray-absorption nearedge structure. Phys. Rev. B 58, 7565-7576. doi:10.1103/PhysRevB.58.7565

Au, Y. S., Obbink, M. K., Srinivasan, S., Magusin, P. C. M. M., de Jong, K. P., and de Jongh, P. E. (2014). The size dependence of hydrogen mobility and sorption kinetics for carbon-supported $\mathrm{MgH}_{2}$ particles. Adv. Funct. Mater. 24, 3604-3611. doi:10.1002/adfm.201304060

Bastide, S., Zlotea, C., Laurent, M., Latroche, M., and Cachet-Vivier, C. (2013). Direct assessment from cyclic voltammetry of size effect on the hydrogen sorption properties of Pd nanoparticle/carbon hybrids. J. Electroanal. Chem. 706, 33-39. doi:10.1016/j.jelechem.2013.07.036

Bérubé, V., Radtke, G., Dresselhaus, M., and Chen, G. (2007). Size effects on the hydrogen storage properties of nanostructured metal hydrides: a review. Int. J. Energy Res 31, 637-663. doi:10.1002/er.1284

Borgschulte, A. (2016). The hydrogen grand challenge. Front. Energy Res. 4:11. doi:10.3389/fenrg.2016.00011

Campesi, R., Cuevas, F., Gadiou, R., Leroy, E., Hirscher, M., Vix-Guterl, C., et al. (2008). Hydrogen storage properties of Pd nanoparticle/carbon template composites. Carbon N. Y. 46, 206-214. doi:10.1016/j.carbon.2007.11.006

Cappillino, P. J., Lavernia, E. J., Ong, M. D., Wolfer, W. G., and Yang, N. Y. (2014). Plastic deformation and hysteresis for hydrogen storage in $\mathrm{Pd}-\mathrm{Rh}$ alloys. J. Alloys Compd. 586, 59-65. doi:10.1016/j.jallcom.2013.10.033

Cheng, F., Tao, Z., Liang, J., and Chen, J. (2012). Efficient hydrogen storage with the combination of lightweight $\mathrm{Mg} / \mathrm{MgH}_{2}$ and nanostructures. Chem. Commun. 48 , 7334-7343. doi:10.1039/c2cc30740e

Contescu, C. I., van Benthem, K., Li, S., Bonifacio, C. S., Pennycook, S. J., Jena, P., et al. (2011). Single Pd atoms in activated carbon fibers and their contribution to hydrogen storage. Carbon N. Y. 49, 4050-4058. doi:10.1016/j. carbon.2011.05.021

Crivello, J.-C., Dam, B., Denys, R. V., Dornheim, M., Grant, D. M., Huot, J., et al. (2016). Review of magnesium hydride-based materials: development and optimisation. Appl. Phys. A 122, 97. doi:10.1007/s00339-016-9602-0

de Jongh, P. E., and Adelhelm, P. (2010). Nanosizing and nanoconfinement: new strategies towards meeting hydrogen storage goals. ChemSusChem 3, 1332-1348. doi:10.1002/cssc.201000248

de Jongh, P. E., Allendorf, M., Vajo, J. J., and Zlotea, C. (2013). Nanoconfined light metal hydrides for reversible hydrogen storage. MRS Bull. 38, 488-494. doi: $10.1557 / \mathrm{mrs} .2013 .108$

de Jongh, P. E., and Eggenhuisen, T. M. (2013). Melt infiltration: an emerging technique for the preparation of novel functional nanostructured materials. Adv. Mater. 25, 6672-6690. doi:10.1002/adma.201301912

de Jongh, P. E., Wagemans, R. W. P., Eggenhuisen, T. M., Dauvillier, B. S., Radstake, P. B., Meeldijk, J. D., et al. (2007). The preparation of carbon-supported magnesium nanoparticles using melt infiltration. Chem. Mater. 19, 6052-6057. doi:10.1021/cm702205v

Driessen, A., Sanger, P., Hemmes, H., and Griessen, R. (1990). Metal hydride formation at pressures up to 1 Mbar. J. Phys. Condens. Matter 2, 9797-9814. doi:10.1088/0953-8984/2/49/007
As it concerns the access and use of ROCK beam line at SOLIL synchrotron, this work was supported by a public grant overseen by the French National Research Agency (ANR) as part of the "Investissements d'Avenir" program (reference: ANR-10-EQPX-45).

\section{SUPPLEMENTARY MATERIAL}

The Supplementary Material for this article can be found online at http://journal.frontiersin.org/article/10.3389/fenrg.2016.00024

Eberle, U., Felderhoff, M., and Schuth, F. (2009). Chemical and physical solutions for hydrogen storage. Angew. Chem. Int. Ed. 48, 6608-6630. doi:10.1002/ anie. 200806293

Essinger-Hileman, E. R., DeCicco, D., Bondi, J. F., and Schaak, R. E. (2011). Aqueous room-temperature synthesis of $\mathrm{Au}-\mathrm{Rh}, \mathrm{Au}-\mathrm{Pt}, \mathrm{Pt}-\mathrm{Rh}$, and $\mathrm{Pd}-\mathrm{Rh}$ alloy nanoparticles: fully tunable compositions within the miscibility gaps. J. Mater. Chem. 21, 11599-11604. doi:10.1039/c0jm03913f

Evans, J., and Tromp, M. (2008). Interaction of small gas phase molecules with alumina supported rhodium nanoparticles: an in situ spectroscopic study. J. Phys. Condens. Matter 20, 184020. doi:10.1088/0953-8984/20/18/184020

Fontaine, C. L., Barthe, L., Rochet, A., and Briois, V. (2013). X-ray absorption spectroscopy and heterogeneous catalysis: performances at the SOLEIL's SAMBA beamline. Catal. Today 205, 148-158. doi:10.1016/j.cattod. 2012.09.032

Frenkel, A. I., Hills, C. W., and Nuzzo, R. G. (2001). A view from the inside: complexity in the atomic scale ordering of supported metal nanoparticles. J. Phys. Chem. B 105, 12689-12703. doi:10.1021/jp012769j

Ghimbeu, C. M., Zlotea, C., Gadiou, R., Cuevas, F., Leroy, E., Latroche, M., et al. (2011). Understanding the mechanism of hydrogen uptake at low pressure in carbon/palladium nanostructured composites. J. Mater. Chem. 21, 1776517775. doi:10.1039/c1jm12939b

Kobayashi, H., Yamauchi, M., and Kitagawa, H. (2012a). Finding hydrogen-storage capability in iridium induced by the nanosize effect. J. Am. Chem. Soc. 134, 6893-6895. doi:10.1021/ja302021d

Kobayashi, H., Morita, H., Yamauchi, M., Ikeda, R., Kitagawa, H., Kubota, Y., et al. (2012b). Nanosize-induced drastic drop in equilibrium hydrogen pressure for hydride formation and structural stabilization in Pd-Rh solid-solution alloys. J. Am. Chem. Soc. 134, 12390-12393. doi:10.1021/ja305031y

Konarova, M., Tanksale, A., Norberto Beltramini, J., and Qing Lu, G. (2012). Effects of nano-confinement on the hydrogen desorption properties of $\mathrm{MgH}_{2}$. Nano Energy 2, 98-104. doi:10.1016/j.nanoen.2012.07.024

Langhammer, C., Zhdanov, V. P., Zoric, I., and Kasemo, B. (2010). Size-dependent kinetics of hydriding and dehydriding of Pd nanoparticles. Phys. Rev. Lett. 104, 135502. doi:10.1103/PhysRevLett.104.135502

Michalowicz, A., Moscovici, J., Muller-Bouvet, D., and Provost, K. (2009). MAX: multiplatform applications for XAFS. J. Phys. Conf. Ser. 190, 012034. doi:10.1088/1742-6596/190/1/012034

Michalowicz, A., Moscovici, J., Muller-Bouvet, D., and Provost, K. (2013). MAX (multiplatform applications for XAFS) new features. J. Phys. Conf. Ser. 430, 012016. doi:10.1088/1742-6596/430/1/012016

Moretto, P., Zlotea, C., Dolci, F., Amieiro, A., Bobet, J.-L., Borgschulte, A., et al. (2013). A round Robin test exercise on hydrogen absorption/desorption properties of a magnesium hydride based material. Int. J. Hydrogen Energy 38, 6704-6717. doi:10.1016/j.ijhydene.2013.03.118

Narehood, D. G., Kishore, S., Goto, H., Adair, J. H., Nelson, J. A., Gutierrez, H. R., et al. (2009). X-ray diffraction and $\mathrm{H}$-storage in ultra-small palladium particles. Int. J. Hydrogen Energy 34, 952-960. doi:10.1016/j.ijhydene.2008.10.080

Nielsen, T. K., Manickam, K., Hirscher, M., Besenbacher, F., and Jensen, T. R. (2009). Confinement of $\mathrm{MgH}_{2}$ nanoclusters within nanoporous aerogel scaffold materials. ACS Nano 3, 3521-3528. doi:10.1021/nn901072w

Noh, H., Flanagan, T. B., Cerundolo, B., and Craft, A. (1991). Hydrogen-induced metal atom mobility in palladium-rhodium alloys. Scr. Metall. Mater. 25, 225-230. doi:10.1016/0956-716X(91)90385-E 
Noh, H., Luo, W., and Flanagan, T. B. (1993). The effect of annealing pretreatment of Pd-Rh alloys on their hydrogen solubilities and thermodynamic parameters for H2 solution. J. Alloys Compd. 196, 7-16. doi:10.1016/0925-8388(93)90562-2

Oumellal, Y., Joubert, J.-M., Matei Ghimbeu, C., Le Meins, J.-M., Bourgon, J., and Zlotea, C. (2016). Synthesis and stability of Pd-Rh nanoalloys with fully tunable particle size and composition. Nano-Structures \& Nano-Objects. doi:10.1016/j. nanoso.2016.06.005

Oumellal, Y., Zlotea, C., Bastide, S., Cachet-Vivier, C., Leonel, E., Sengmany, S., et al. (2014). Bottom-up preparation of $\mathrm{MgH}_{2}$ nanoparticles with enhanced cycle life stability during electrochemical conversion in Li-ion batteries. Nanoscale 6, 14459-14466. doi:10.1039/C4NR03444A

Pundt, A., and Kirchheim, R. (2006). Hydrogen in metals: microstructural aspects. Annu. Rev. Mater. Res. 36, 555-608. doi:10.1146/annurev. matsci.36.090804.094451

Raub, E. (1959). Metals and alloys of the platinum group. J. Less Common Met. 1, 3-18. doi:10.1016/0022-5088(59)90014-1

Roduner, E. (2006). Size matters: why nanomaterials are different. Chem. Soc. Rev. 35, 583-592. doi:10.1039/b502142c

Roesler, C., and Fischer, R. A. (2015). Metal-organic frameworks as hosts for nanoparticles. CrystEngComm 17, 199-217. doi:10.1039/C4CE01251H

Sachs, C., Pundt, A., Kirchheim, R., Winter, M., Reetz, M. T., and Fritsch, D. (2001). Solubility of hydrogen in single-sized palladium clusters. Phys. Rev. B 64, 075408. doi:10.1103/PhysRevB.64.075408

Sartori, S., Cuevas, F., and Latroche, M. (2016). Metal hydrides used as negative electrode materials for Li-ion batteries. Appl. Phys. A 122, 1-7. doi:10.1007/ s00339-016-9674-x

Sayers, D. E. (2000). Report of the International XAFS Society Standards and Criteria Commitee. Available at: http://ixs.iit.edu/subcommittee_reports/sc/ SC00report.pdf

Wilcoxon, J. P., and Abrams, B. L. (2006). Synthesis, structure and properties of metal nanoclusters. Chem. Soc. Rev. 35, 1162-1194. doi:10.1039/b517312b

Yamauchi, M., Ikeda, R., Kitagawa, H., and Masaki, T. (2008). Nanosize effects on hydrogen storage in palladium. J. Phys. Chem. C 112, 3294-3299. doi:10.1021/ jp710447j

Zhang, S., Gross, A. F., Van Atta, S. L., Lopez, M., Liu, P., Ahn, C. C., et al. (2009). The synthesis and hydrogen storage properties of a $\mathrm{MgH}_{2}$ incorporated carbon aerogel scaffold. Nanotechnology 20, 204027. doi:10.1088/0957-4484/20/20/204027

Zhao, W., Fierro, V., Zlotea, C., Izquierdo, M. T., Chevalier-Cesar, C., Latroche, M., et al. (2012). Activated carbons doped with Pd nanoparticles for hydrogen storage. Int. J. Hydrogen Energy 37, 5072-5080. doi:10.1016/j.ijhydene.2011.12.058

Zlotea, C., Campesi, R., Cuevas, F., Leroy, E., Dibandjo, P., Volkringer, C., et al. (2010a). Pd nanoparticles embedded into a metal-organic framework: synthesis, structural characteristics, and hydrogen sorption properties. J. Am. Chem. Soc. 132, 2991-2997. doi:10.1021/ja9084995
Zlotea, C., Cuevas, F., Paul-Boncour, V., Leroy, E., Dibandjo, P., Gadiou, R., et al (2010b). Size-dependent hydrogen sorption in ultrasmall Pd clusters embedded in a mesoporous carbon template. J. Am. Chem. Soc. 132, 7720-7729. doi:10.1021/ja101795g

Zlotea, C., Chevalier-Cesar, C., Leonel, E., Leroy, E., Cuevas, F., Dibandjo, P., et al. (2011). Synthesis of small metallic Mg-based nanoparticles confined in porous carbon materials for hydrogen sorption. Faraday Discuss. 151, 117-131. doi:10.1039/c0fd00016g

Zlotea, C., Cuevas, F., Andrieux, J., Ghimbeu, C. M., Leroy, E., Leonel, E., et al. (2013). Tunable synthesis of (Mg-Ni)-based hydrides nanoconfined in templated carbon studied by in situ synchrotron diffraction. Nano Energy 2, 12-20. doi:10.1016/j.nanoen.2012.07.005

Zlotea, C., and Latroche, M. (2013). Role of nanoconfinement on hydrogen sorption properties of metal nanoparticles hybrids. Colloids Surf. A Physicochem. Eng. Asp. 439, 117-130. doi:10.1016/j. colsurfa.2012.11.043

Zlotea, C., Morfin, F., Nguyen, T. S., Nguyen, N. T., Nelayah, J., Ricolleau, C., et al. (2014). Nanoalloying bulk-immiscible iridium and palladium inhibits hydride formation and promotes catalytic performances. Nanoscale 6, 9955-9959. doi:10.1039/c4nr02836h

Zlotea, C., Oumellal, Y., Hwang, S.-J., Ghimbeu, C. M., de Jongh, P. E., and Latroche, M. (2015a). Ultrasmall $\mathrm{MgH}_{2}$ nanoparticles embedded in an ordered microporous carbon exhibiting rapid hydrogen sorption kinetics. J. Phys. Chem. C 119, 18091-18098. doi:10.1021/acs.jpcc.5b05754

Zlotea, C., Oumellal, Y., Msakni, M., Bourgon, J., Bastide, S., CachetVivier, C., et al. (2015b). First evidence of Rh nano-hydride formation at low pressure. Nano Lett. 15, 4752-4757. doi:10.1021/acs. nanolett. 5 b0 1766

Zlotea, C., Ghimbeu, C. M., Oumellal, Y., Crivello, J.-C., Vix-Guterl, C., and Latroche, M. (2015c). Hydrogen sorption properties of Pd-Co nanoalloys embedded into mesoporous carbons. Nanoscale 7, 15469-15476. doi:10.1039/ c5nr03143e

Conflict of Interest Statement: The authors declare that the research was conducted in the absence of any commercial or financial relationships that could be construed as a potential conflict of interest.

Copyright (c) 2016 Zlotea, Oumellal, Provost and Ghimbeu. This is an open-access article distributed under the terms of the Creative Commons Attribution License (CC BY). The use, distribution or reproduction in other forums is permitted, provided the original author(s) or licensor are credited and that the original publication in this journal is cited, in accordance with accepted academic practice. No use, distribution or reproduction is permitted which does not comply with these terms. 